\title{
Control judicial de las reglas de la sana crítica (Corte Suprema)
}

\section{Comentario de Iván Hunter Ampuero}

Santiago, veintinueve de mayo de dos mil doce.

VISTOS: En estos autos rol No 8339-2009 sobre juicio ordinario de reparación de daño ambiental seguido en contra de Tribasa Cono Sur S.A., el Consejo de Defensa del Estado, en representación del Estado de Chile, interpuso recurso de casación en el fondo contra la sentencia de la Corte de Apelaciones de Concepción que confirmó la de primer grado que rechazó la demanda, en razón que, pese a que se encuentra acreditado el daño medioambiental, no ocurrió así con la responsabilidad que se le atribuye a la demandada.

Se trajeron los autos en relación.

\section{CONSIDERANDO:}

PRIMERO: Que el recurso denuncia la infracción del artículo 45 del Código Civil en cuanto se acoge la excepción de caso fortuito invocada por la demandada.

Sostiene que el error se origina porque la única forma de considerar el caso fortuito como causal eximente se produce cuando "sobreviene un hecho de la naturaleza el que la voluntad no puede enfrentar, generándose un perjuicio cuyo antecedente causal no es otro que el indicado acontecimiento", por ello cualquier grado de culpa en que incurra el autor del daño compromete su responsabilidad y obliga a reparar los perjuicios producidos.

Indica que la infracción es patente en la sentencia al señalar la "razón por la que no puede existir certeza respecto a que el daño ambiental tuvo su causa solamente en un actuar infraccional de Tribasa Cono Sur S.A.”.

Refiere que con la prueba documental, testimonial y pericial se encuentra acreditado que el daño es consecuencia del obrar de la demandada al infringir las exigencias que la autoridad le había impuesto, tanto en la resolución de calificación ambiental como en el permiso sectorial para la extracción de áridos, por lo que existe relación directa entre el daño y la infracción de la demandada, lo que no permitía acoger la excepción de caso fortuito.

SEGUNDO: Que en un segundo capítulo invoca la infracción de las normas reguladoras de la prueba. Expresa que el artículo 62 de la Ley $\mathrm{N}^{\circ} 19.300$ ordena que en estos procesos la prueba debe apreciarse conforme a las reglas de la sana crítica.

Indica que en este caso no se han aplicado las reglas de la sana crítica, ya que existe una infracción a las normas de la lógica y máximas de la experiencia pues de que la sentencia de segunda instancia da por configurado el caso fortuito con la crecida del 
río acaecida en el mes de junio de 2000 y con ello establece una ausencia de relación de causalidad entre el daño producido y el actuar de la demandada, en circunstancias que conforme a la prueba rendida se verifica que los daños se producen entre el año 1999 y abril de 2000, siendo la causa del daño ambiental la alteración del eje hidráulico del Río Laja con modificación de su cauce y socavamiento de su ribera izquierda, lo que fue consecuencia directa del obrar de la demandada y no atribuible a un hecho de la naturaleza o caso fortuito.

TERCERO: Que finalmente se invoca la errónea interpretación del artículo 52 de la Ley $\mathrm{N}^{\circ} 19.300$ que establece una presunción de responsabilidad en el caso de quienes infrinjan normas de carácter medioambientales.

Señala que la sentencia de primera instancia en su considerando catorce establece que la presunción sólo es procedente si se acredita la relación de causa a efecto, entre la infracción y el daño producido, por lo que se está incorporando un requisito adicional que no es exigido por la norma para que proceda la presunción, ya que cuando se ejerce la acción de reparación de daño ambiental sólo es necesario acreditar la infracción normativa y el daño, pero no la relación de causalidad entre la infracción y el daño, por cuanto este requisito es exigible cuando se pretende obtener una indemnización de perjuicios, que no es el caso.

CUARTO: Que para resolver útil resulta consignar los siguientes antecedentes del proceso:

a) La presente causa se inicia por demanda del Consejo de Defensa del Estado fundada en que la demandada entre los años 1999 y 2000 ejecutó la actividad de extracción mecanizada de áridos del Río Laja, en un tramo de 3,2 Km., a $35 \mathrm{Km}$. al norte de la ciudad de Los Ángeles en el sector denominado Paraguay, realizando esta actividad sin adoptar los resguardos necesarios e incumpliendo los compromisos ambientales contraídos, con lo que causó y causa un severo daño ambiental consistente en una importante variación del Río Laja en el sector intervenido por la actividad de extracción de áridos que provocó el socavamiento de la ribera izquierda del río como consecuencia de la desviación de las aguas hacia esa ribera, con la pérdida de terrenos cultivables en una extensión de 100 metros de ancho por 400 metros que se perdieron y que se sigue erosionando.

b) El proyecto de la demandada ingresó al sistema de evaluación de impacto ambiental mediante la correspondiente Declaración de Impacto Ambiental presentada ante la Corporación Regional del Medio Ambiente de la VIII Región que lo calificó favorablemente por medio de la Resolución Exenta No 107/98 de 3 de agosto del año 1998 que aprobó la ejecución del proyecto y las obligaciones de ejecutarlo bajo ciertas condiciones y que, por el incumplimiento, comenzó un proceso sancionatorio que culminó con la Resolución Exenta Nº 60/02 de 18 de febrero del año 2002 que aplicó sanciones a la demandada.

c) Que la demandada al contestar señala que ha dado cumplimiento a las exigencias medioambientales que se le hicieron, extrayendo con maquinarias desde el tercio central del cauce del río en canalones de 100 metros cada uno, paralelos al borde 
izquierdo del sello de explotación, efectuando durante las faenas trabajos de protección adicionales a los ordenados por la resolución de la Corporación Regional del Medio Ambiente que aprobó el proyecto, destinados a estabilizar los taludes ribereños y así evitar inundaciones en los predios y minimizar cualquier impacto ambiental. Agrega que en el mes de junio del año 2000 se produjeron en el sector las lluvias más intensas que hay registradas desde el año 1975 y que éstas provocaron la crecida instantánea del río, ocasionando que las aguas excedieran las riberas, lo que a su juicio constituye un caso fortuito y por ende no hay culpa o dolo que se le pueda imputar para acreditar su responsabilidad. Respecto de la multa señala que ésta fue reclamada obteniendo su rebaja por parte del Cuarto Juzgado Civil de Santiago.

QUINTO: Que los sentenciadores de la instancia decidieron que la prueba rendida -que fuera apreciada conforme a la sana crítica- no permitía concluir fehacientemente la imputabilidad a la demandada respecto del daño ambiental acreditado, lo que los llevó a rechazar la demanda.

SEXTO: Que en el examen de los yerros que denuncia el recurso de nulidad necesario es determinar si se estructura la responsabilidad medioambiental de la demandada, lo que lleva a analizar la denunciada infracción de las reglas de la sana crítica en la apreciación de las pruebas aportadas al proceso.

SÉPTIMO: Que la Ley $\mathrm{N}^{\circ} 19.300$ en el artículo 62 inciso primero vigente al sustanciarse la causa prescribía: "El juez apreciará la prueba conforme a las reglas de la sana crítica y será admisible cualquier medio de prueba, además de los establecidos en el Código de Procedimiento Civil". En la sana crítica el juez tiene la obligación de explicitar las razones lógicas, científicas y de experiencia por medio de las cuales obtuvo su convicción, exteriorizando las argumentaciones que le sirven de fundamento, analizando y ponderando toda la prueba rendida de una forma integral, tanto de la que le sirve de sustento como la que se descarta, teniendo en especial consideración la multiplicidad, gravedad, precisión y concordancia de la prueba rendida.

De lo anterior se puede concluir que la inobservancia o transgresión de tales parámetros, como su equivocada aplicación, puede implicar una contravención a la ley que privará de fuerza a la decisión jurisdiccional así alcanzada.

OCTAVO: Que enseguida habrá de determinarse si en la especie se produjo la transgresión de aquellos parámetros antes anotados como aduce la recurrente y resolver, en consecuencia, si la demandada debe responder por el daño ambiental que se le imputa.

En el caso de autos, pese a ser enunciado en la sentencia de primera instancia, el documento incorporado al proceso mediante oficio remitido por la Comisión Regional de Medio Ambiente, consistente en la Resolución Exenta N No $^{\circ} / 02$ de 18 de febrero de 2002, no se ha ponderado adecuadamente por los sentenciadores de la instancia, por cuanto en éste consta la sanción impuesta a la demandada por incumplimiento de las condiciones bajo las cuales 
fue aprobada la Declaración de Impacto Ambiental del proyecto "Extracción mecanizada de áridos Río Laja, sector Paraguay”, lo que se traduce en la aplicación respecto de Tribasa Cono Sur S.A. de lo establecido en el artículo 52 de la Ley $\mathrm{N}^{\circ} 19.300$, correspondiendo a esa parte acreditar su falta de responsabilidad en el daño que se le imputa.

NOVENO: Que, por lo anterior, era de cargo de la parte demandada acreditar que el daño al medio ambiente se debió únicamente a las lluvias a que hace referencia en su defensa y no a la forma en cómo dio ejecución a la extracción de áridos en el Río Laja, por lo que los sentenciadores de la instancia, invirtiendo la carga de la prueba, reprochan al actor el no acreditar la exclusiva responsabilidad de la demandada, pese a que era carga de esta última probar tal circunstancia.

DECIMO: Que, en consecuencia, los jueces al no explicitar los motivos para desestimar la pertinencia y eficacia del valor probatorio de la resolución sancionatoria por daño ambiental, pese a la importancia que se desprende en relación con la presunción establecida en el artículo 52 de la Ley $\mathrm{N}^{\circ} 19.300$, no han hecho un correcto ejercicio de la sana crítica, porque no se han sujetado razonadamente a las normas de la lógica y las máximas de la experiencia.

UNDÉCIMO: Que en armonía con lo dicho yerra también el fallo al acoger la excepción de caso fortuito opuesta por la demandada, toda vez que con los antecedentes antes descritos no es factible a la luz de la prueba rendida acreditar su procedencia.

DUODÉCIMO: Que los errores antes anotados han influido sustancialmente en lo dispositivo del fallo atacado, puesto que si se hubiere ponderado la prueba aportada conforme a los parámetros de la sana crítica se habría concluido que correspondía a la demandada acreditar que no es responsable del daño ambiental determinado, atendida la presunción de responsabilidad que existe en su contra por ser infractor de normas ambientales, lo que no hizo.

Por estas consideraciones y lo dispuesto en los artículos 764, 765, 785 y 805 del Código de Procedimiento Civil, se acoge el recurso de casación en el fondo interpuesto en lo principal de la presentación de fojas 1198 contra la sentencia de cuatro de septiembre de dos mil nueve, escrita a fojas 1.196 y siguiente, la que por consiguiente es nula y se la reemplaza por la que se dicta a continuación.

Acordado lo anterior con el voto en contra del Ministro señor Brito, quien estuvo por rechazar el recurso de autos en virtud a las siguientes consideraciones:

1. En el sistema de valoración probatoria denominado de sana crítica -mejor llamado, de apreciación razonada- los jueces, no obstante encontrarse liberados de las restricciones inmanentes al de la prueba reglada o tasada, están jurídicamente sujetos a la observancia de los parámetros que impone el respeto a las reglas de la lógica, las máximas de la experiencia y el conocimiento científico afianzado, en lo que se refiere al modo de apreciar las probanzas y a la adopción de las subsecuentes conclusiones. 
De manera que la labor de establecer si la prueba traduce la verdad o falsedad de un determinado enunciado fáctico según las reglas de la sana crítica no implica irracionalidad para dejarse llevar por la sola intuición. "El juez que debe decidir con arreglo a la sana crítica, no es libre de razonar a voluntad, discrecionalmente, arbitrariamente" (Couture, Eduardo, "Obras. Tomo I. Fundamentos del Derecho Procesal Civil”, Edit. Thomson Reuters Puntolex, Año 2010, p. 244). El juez debe valorar la prueba limitado por las reglas que impone el sistema de sana crítica.

La primera de éstas son las llamadas "reglas de la lógica". Forman partes de ella la regla de la identidad, por la cual se asegura que una cosa sólo puede ser lo que es y no otra; la regla de la (no) contradicción, por la que se entiende que una cosa no puede entenderse en dos dimensiones, como ser falsa o verdadera, al mismo tiempo; la regla del tercero excluido, la cual establece que entre dos proposiciones en la cual una afirma y otra niega, una de ellas debe ser verdadera; y, la regla de la razón suficiente, por la cual cualquier afirmación o proposición que acredite la existencia o no de un hecho debe estar fundamentada en una razón que la acredite suficientemente.

Mediante este conjunto de reglas se asegura formalmente la corrección del razonamiento -que partiendo de premisas verdaderas se arribe a conclusiones correctas- que se espera siempre tenga lugar y que, por lo demás, otorgan inequívoca objetividad a la labor de ponderación. El examen lógico formal de la argumentación del juez permite un control de la valoración que éste haya hecho de las pruebas rolantes en el proceso. Por ello se afirma que la exigencia de corrección en la valoración de las probanzas de acuerdo a las reglas de la lógica constituye una verdadera garantía para aquellos que están siendo juzgados.

La segunda regla, conocida como "máximas de la experiencia", se refiere a "un criterio objetivo, interpersonal o social [...] que son patrimonio del grupo social [.] de la psicología, de la física y de otras ciencias experimentales” (Devis Echandía, Hernando, “Teoría General de la Prueba Judicial”, Edit. Zavalia, Buenos aires, 1981, T. I, p. 336).

Finalmente, la tercera regla obedece al denominado "conocimiento científico afianzado”. Esta hace alusión a saberes técnicos, que han sido respaldados por el mundo científico. Por su propia naturaleza este conocimiento también goza del mismo carácter objetivo que las reglas de la lógica.

Ninguna de estas tres directrices es suficiente por sí misma. La corrección lógica de la valoración probatoria no excusa del error ni de la injusticia cuando se aplica aisladamente. Las máximas de la experiencia son esencialmente mutables, en tanto la experiencia humana es también forzosamente variable, y por ello tampoco escapan del error. El conocimiento científicamente afianzado, por último, aunque respaldado por la objetividad, tampoco es infalible; su estabilidad y contradictoriedad están en directa relación con los avances de la ciencia. De manera que utilizar sólo esta última regla, sin una corrección lógica que la sustente y una consideración a las máximas de la experiencia que la fundamente, tampoco salva del error o la inexactitud a la prueba así valorada. Una correcta ponderación de acuerdo a la sana crítica implica necesariamente una conjugación de estas reglas.

Se evidencia de este modo que el sistema de sana crítica, no obstante la mayor amplitud en el margen de libertad otorgado para ponderar la prueba, impone reglas concretas 
y claras que no pueden ser desconocidas por los jueces al momento de utilizarlo. No es un sistema enteramente libre -y por tanto subjetivo- como el que faculta, por ejemplo, para apreciar la prueba en conciencia. Por ello Couture afirma que está a medio camino entre el sistema legal tasado y el de libre convicción: "Sin los excesos de la prueba legal, que llevan muchas veces a consagrar soluciones contrarias a la convicción del juez, pero también sin los excesos a que la arbitrariedad del magistrado podría conducir en el método de la libre convicción tomado en un sentido absoluto [...]" (Couture, Eduardo, "Obras. Tomo I. Fundamentos del Derecho Procesal Civil”, Edit. Thomson Reuters Puntolex, Año 2010, p. 249).

Precisamente por constituir un sistema reglado-objetivamente- por la lógica, la experiencia y el conocimiento científicamente respaldado, su utilización por el juez es siempre controlable por esta vía.

2. En efecto, la norma legal que previene el sistema probatorio, así como el modo en que opera y las reglas que lo componen, es de carácter sustantiva y a ella ha de adecuarse la labor de ponderación. Ello es así, porque la sola referencia de la norma al sistema de la sana crítica incorpora al precepto que lo establece, todas las reglas que la constituyen, que le son propias e indiscutibles. De ahí que siempre sea posible examinar por vía de casación su aplicación. Así lo ha sostenido, por lo demás, en diversas ocasiones esta corte: por ejemplo, en los ingresos de fecha 27 de octubre de 1998, caratulados "Contra Rojas Castro, Claudia Bernardita"; de 7 de enero de 1999, caratulados "Contra Carreño Durán, Dioselinda"; de 13 de abril del año 2000, caratulados "Contra Urrutia Urrutia, Jorge Ignacio"; y de 18 de mayo del año 2000, caratulados "Contra Sáez Ramírez, Luis Patricio", entre otros.

Verificar la adecuación del sistema de valoración probatoria a las reglas de la sana crítica no implica valorar nuevamente los hechos, pues tal labor excedería los márgenes del recurso y la competencia de este tribunal. En la especie, controlar la valoración de la prueba implica comprobar si el razonamiento jurídico del juez se ha adecuado a las reglas que impone el sistema de sana crítica; en otras palabras: examinar cómo han gravitado y qué influencia han ejercido los medios de prueba en él a la hora de arribar a la decisión que ha consignado en la sentencia. Ello fuerza a revisar la manera o forma en que se han ponderado las pruebas, mas no el material fáctico de la ponderación. No se revisan los hechos, sino la aplicación del derecho, en cuanto establece la forma de ponderar, labor que ha de hacerse sin valorar. Si el artículo 62 de la Ley $\mathrm{N}^{\circ} 19.300$ obliga al juez a dictar sentencia de acuerdo con estas reglas, limitando la discrecionalidad del juez a la hora de valorar la prueba, el recurso de casación en el fondo no tiene otro objeto más que custodiar el respeto y la correcta aplicación de esta norma en el razonamiento que se consigna en la sentencia.

De forma tal que, sólo si se logra determinar que el juez ha dado falsa o incorrecta aplicación, o derechamente ha dejado de aplicar las reglas de la sana crítica, y ello ha influido sustancialmente en la decisión, se estará en condiciones de acoger el recurso de casación en el fondo y dictar, consecuentemente, sentencia de reemplazo; en la cual recién se podrán conocer nuevamente los hechos, es decir, valorar. 
3. El recurso de autos, entonces, para prosperar debió postular una tesis encaminada a demostrar que el razonamiento del fallo contrariaba las reglas de la lógica, las máximas de la experiencia o el conocimiento científicamente afianzado, y que su inobservancia incidía en lo dispositivo del fallo.

En la especie, por el contrario, la impugnación se apoyó en una cuestión de valoración del instrumento referido en el motivo octavo de este fallo, y no en la vulneración a las leyes de la lógica o las máximas de la experiencia y el conocimiento científicamente afianzado. Esta forma de fundamentar el recurso, atendido que no compete a esta Corte ponderar probanzas, obliga a desestimarlo.

4. Por otra parte, también es claro que la demandante aportó al pleito los hechos en que fundamentó la acción ambiental de que se trata, el incumplimiento de las condiciones establecidas a propósito de la declaración de impacto ambiental, por lo que no es procedente exigir la prueba del caso fortuito que releva de responsabilidad si previamente no ha sido probado aquel presupuesto fáctico.

Regístrese.

Redacción a cargo del Ministro señor Pierry y de la disidencia, su autor.

Rol No 8339-2009.

Pronunciado por la Tercera Sala de esta Corte Suprema, integrada por los Ministros Sr. Héctor Carreño S., Sr. Pedro Pierry A., Sra. Sonia Araneda B., Sr. Haroldo Brito C. y Sra. María Eugenia Sandoval G. No firma, no obstante haber concurrido a la vista y al acuerdo de la causa, el Ministro señor Carreño por estar con permiso. Santiago, 29 de mayo de 2012.

Autoriza la Ministra de Fe de la Excma. Corte Suprema.

\section{COMENTARIO}

La sentencia que se comenta tiene varias aristas que resultan dignas e importantes de analizar. Preliminarmente es necesario indicar que para nadie es novedad que nuestro sistema procesal ha comenzado a tener una profunda y paulatina reforma orientada sectorialmente con miras a satisfacer aquellos bienes propios de cada rama. Esta evolución contrasta con la regulación de la prueba, la que sigue una idéntica dirección. Así, prácticamente todos los procedimientos han adoptado un sistema de valoración libre (sana crítica) abandonando los sistemas de corte decimonónico basados en la tasación legislativa de los medios de prueba más importantes. Esto implica, en sencillas palabras, depositar en los jueces una confianza poco inusual para una tradición judicial acostumbrada a la seguridad jurídica, aparentemente conquistada mediante reglas que definían previamente el valor verdad de los medios de prueba. Esta confianza en los jueces ha ido acompañada de fuertes exigencias de motivación de las sentencias y es en este último asunto donde quiero centrar mi análisis.

El voto de mayoría de la Corte Suprema acoge el recurso de casación en el fondo entendiendo que existe una infracción a las normas que regulan la valoración de la prueba conforme a la sana crítica, y específicamente, estimando que no se ha ponderado adecuadamente un 
determinado documento. Esta línea argumental, en el alero del recurso de casación en el fondo, resulta inadmisible. Existe un cúmulo importante de decisiones judiciales que han resaltado la imposibilidad de la Corte Suprema de controlar el ámbito de libertad en la valoración de los medios de prueba que es entregada a los jueces de la instancia ${ }^{1}$. No se comprende que nuestro Máximo Tribunal entre a valorar la determinación de los hechos en un sistema de apreciación libre, amparándose en una supuesta infracción a la sana crítica. Por eso, el voto de disidencia camina, a mi juicio, por el derrotero correcto. La ausencia de ponderación en la valoración y motivación de un determinado medio de prueba no equivale a la infracción de las normas de la sana crítica. Es paradójico que en un sistema de apreciación libre de la prueba la Corte Suprema se sienta más autorizada a entrar en la revisión de los hechos que en un sistema de prueba legal o tasada, como el actual.

Del considerando séptimo del fallo de mayoría pueden formularse dos comentarios: uno relativo al concepto de motivación y otro en relación a la amplitud de la motivación en relación al material probatorio producido en el proceso. Respecto del primero me surgen dudas acerca de qué entiende nuestra Corte Suprema por motivación, pues las expresiones "explicitar", "convicción” y "exteriorización” de argumentaciones, constituyen una tríada que acerca la motivación a un discurso que tendría por objeto dar cuenta de los procesos mentales o de los estados psicológicos que sustentan una decisión, una suerte de reconstrucción de los procesos internos que llevan a los jueces a decidir de una determinada manera. De esta forma, una decisión sería justificada (motivada) cuando describe el proceso mental del juez, y "la decisión quedaría válidamente justificada en cuanto fuera la adecuada descripción de un proceso mental lógica y jurídicamente correcto" ${ }^{2}$. Esta forma de entender la motivación ha sido duramente cuestionada por la doctrina, ya que ésta no consiste en una descripción de procesos mentales, sino en un ejercicio de justificación racional de decisiones ${ }^{3}$. En este sentido se puede decir que la motivación "consiste precisamente en un discurso justificativo en que el juez enuncia y desarrolla las 'buenas razones' que fundamentan la legitimidad y la racionalidad de la decisión” ${ }^{\text {. }}$ La motivación corresponde, esencialmente, a un discurso justificativo estructurado sobre explicaciones racionales; el juez debe articular en la sentencia un conjunto de razones

${ }^{1}$ Vid., entre otros fallos: C. Suprema, 4 octubre 1904. R., t. 1, sec. $1^{\text {a }}$, p. 110 ; C. Suprema, 27 junio 1983. R., t. 80, sec. $1^{\text {a }}$, p. 42; C. Suprema, 19 marzo 1984. R., t. 81, sec. 1a , p. 41. C. Suprema, 20 junio 1984. R., t. 81, sec. $1^{\text {a }}$, p. 91. C. Suprema, 30 mayo 1953. R., t. 50, sec. 1a, p. 173; C. Suprema, 8 septiembre 1954. R., t. 51, sec. $1^{\text {a }, ~ p . ~ 433 ; ~ C . ~ S u p r e m a, ~} 3$ mayo 1957. R., t. 54, sec. $1^{\text {a }}$, p. 71; C. Suprema, 25 julio 1960. R., t. 58, sec. $1^{\text {a }}$, p. 95; C. Suprema, 13 julio 1962. R., t. 59, sec. $1^{\text {a }}$, p. 219; C. Suprema, 13 noviembre 1963. R., t. 60, sec. $1^{\text {a }}$, p. 340; C. Suprema, 10 agosto 1965 . R., t. 62, sec. $1^{\text {a }}$, p. 268; C. Suprema, 4 septiembre 1965. R., t. 62 , sec. $1^{\text {a }}$, p. 305; C. Suprema, 6 abril 1988. R., t. 85, sec. $1^{\text {a }}$, p. 50; C. Suprema, 18 abril 1988. R., t. 85, sec. $1^{\text {a }}$, p. 57; C. Suprema, 22 marzo 1989. R., t. 86, sec. 1a, p. 44; C. Suprema, 9 noviembre 1993. R., t. 90 , sec. $1^{\text {a }}$, p. 129, y C. Suprema, 10 agosto 1965. R., t. 62, sec. $1^{\text {a }}$, p. 268.

${ }^{2}$ Igartua, J., Valoración de la prueba, motivación y control en el proceso penal, Tirant lo Blanch, Valencia, 1994, p. 147. El autor tiene, no obstante, un sentido bastante crítico a esta forma de entender la motivación de las sentencias.

3 Ibid., p. 148, y Taruffo, M., Simplemente la verdad, Marcial Pons, Madrid, 2010, p. 267.

${ }^{4}$ Taruffo, M., Páginas sobre justicia civil, Marcial Pons, Madrid, 2010, p. 520. 
posibles de ser compartidas por los distintos sujetos que participan en el desarrollo del proceso y que tiendan a justificar su decisión. Nada tiene que ver, entonces, con la explicitación de procesos mentales.

El segundo aspecto que cabe destacar se refleja en la plenitud de la motivación. Aquí existe una clara empatía entre lo que dice la doctrina y lo que afirma la jurisprudencia. La doctrina ha precisado que no basta con cualquier motivación para satisfacer las exigencias constitucionales; es indispensable que sea completa, esto es, abarcar todos los aspectos fácticos y jurídicos de la decisión. En concreto, se trata que el razonamiento para determinar la verdad de un enunciado fáctico pueda encontrarse suficiente y adecuadamente justificado con las pruebas producidas en el proceso. El razonamiento justificativo tiene que ser apto para demostrar que los enunciados declarados verdaderos tienen un sustento en el material probatorio 5 . De ahí que el juez deba analizar, valorar y ponderar todos los medios de prueba generados en el proceso. Pero la Corte va más allá al exigir que el juez deba hacerse cargo incluso de la prueba que se "descarta". Esta exigencia puede tener una doble lectura. Una lectura preliminar sería coherente con la dinámica del actual procedimiento civil, donde no existe una fase de admisibilidad a la prueba ofrecida por las partes ${ }^{6}$, por lo que suele ser frecuente que la decisión sobre los hechos, y en especial la valoración de la prueba, se mezcle con cuestiones relativas a la pertinencia y utilidad de la misma. De esta forma, la motivación alcanzaría a la justificación de las razones de por qué un medio de prueba puede ser considerado inútil e irrelevante. La segunda lectura, no necesariamente incompatible con la anterior, es entender que nuestro Máximo Tribunal está descartando la validez de la denominada motivación implícita. Esta tiene lugar "cuando la determinación de un hecho o la valoración de una prueba, a los que el juez no se refiere, serían incompatibles con otro hecho, o con otra prueba, a los que la motivación sí hace referencia" 7 . Este tipo de motivación suele ser frecuente en la práctica de nuestros tribunales de justicia, y es una clara privación al derecho a la sentencia motivada; que el juez justifique la existencia de un hecho mediante las pruebas disponibles, no excluye la exigencia de motivar la prueba destinada a confirmar la existencia (o falsedad) de un hecho incompatible con el declarado verdadero.

Creo que esta sentencia, más allá de la incorrección técnico-jurídica de su decisión y de la necesidad de ir puliendo el concepto de motivación, va en el camino correcto para desarrollar un sistema de motivación capaz de satisfacer los umbrales constitucionales. Queda fijado aquí un concepto elemental como es la completitud de la motivación. Ojalá en el futuro nuestro Máximo Tribunal pueda pronunciarse sobre los otros aspectos de la motivación con la finalidad de completar un modelo que sirva a los mismos jueces para justificar en forma constitucionalmente adecuada sus decisiones.

5 Taruffo, M., Simplemente la verdad, op. cit., p. 270.

${ }^{6}$ Como parece ser frecuente en la práctica judicial es común observar que los expedientes judiciales se agobian de material probatorio incorporado sin ningún tipo de examen previo de admisibilidad, especialmente la documental. A esto se une que las partes no suelen orientar al juez, pues ni siquiera indican el o los hechos que se desean probar con la prueba que producen.

7 Taruffo, M., Simplemente la verdad, op. cit., p. 270. 